\title{
Alternative solution for deforestation: under soil house as architecture experimental design
}

\author{
Farouk Irfan Almunir ${ }^{1, *}$, Hena Safna Federlina ${ }^{1}$, M. Syaom Barliana ${ }^{1}$, and Indah Susanti ${ }^{1}$ \\ ${ }^{1}$ Universitas Pendidikan Indonesia, Architecture Program, Departemen Pendidikan Teknik Arsitektur, FPTK
}

\begin{abstract}
Architecture is a built environment to fulfil the needs of human inhabitants. However, behind the aesthetics of beauty artificial that formed, the inherent in it, architecture has different impact to the nature related with destruction. Rapid deforestation has its way alongside with the build of housing, agriculture, and industry. To answer the related problem, the experimental study should be offered. Therefore, this paper puts forward the solution for the undersoil house design. In the future, people might adapt with unpredicted condition, so ask the new design to leave must be set up in an experimental manner.
\end{abstract}

\section{Background}

Architecture will always find problem to be solved. Architect has always been a hegemony in solving problems of his time, In the course of architecture always finds new problems, but sometimes it is not realized that architecture always brings a problem that never escape until now. Behind the architectural masterpiece on behalf of artificial beauty, there architecture kills nature and its ecosystem slowly and continuously.

The occurrence of the killings (deforestation: the process of removing natural forests by logging for timber harvesting or converting forest land into non-forested land) indicates a developmental dissonance between the magnificent works of architecture (city) and forest [1]. To overcome this, the development between the city and the forest must be balanced and the utilization of resources in the forest should be done wisely.

Deforestation is a forest clearing or stand of trees so that land can be used for non-forest use, i.e. agriculture, livestock or urban areas [1]. Deforestation is a condition when the level of forest area shows a decrease in quality and quantity [2]. Deforestation (deforestation) remains a threat in the world of architecture. Given the data released by various sources, the architecture has swallowed millions of hectares of forest in recent years.

The end architecture (the end architecture) in the world quite threatening. Architecture will always change when its time, and the architect can be threatened in his world. Therefore, to emphasize its role to become a science-friendly field it's time architecture conscious and then responsible for his behavior. The initiative in polluting creates a design that is capable of being applied in large quantities that deserve natural acceptance [2].

To answer the related problem, the experimental study should be offered. Therefore, this paper puts forward the solution for the house design. In the future, people might adapt with unpredicted condition, so ask the new design to leave must be set up in an experimental manner.

\section{Problems}

Based on the background, the problems are:

- How deforestation can threaten the earth?

- How can humans survive, with the issue of deforestation?

- What design solutions (housing principles/systems used) to solved the deforestation issue?

\section{Purpose}

Base on the problems, the purpose of this paper is:

- Explain the impact of deforestation

- Providing an innovation, idea, or concept to problem of deforestation.

- Give an explanation of the design solutions (housing principles/systems used) to solved the deforestation issue.

\section{Design method approach}

The design method used is "Experimental Design". Experimental architecture is one of the branches of the discipline of the science of architecture that was born from the idea of British architect named Peter Cook and his friends since the 1960s. [3] This method emphasizes the development of more creative and challenging concepts, beyond the architectures that are conceptualized by conventional practice. The goal is to explore the purity of the mind of the architect by developing innovations on architectural design methods. The design process involves innovation of thought and a variety of experiments on materials and technology. The

\footnotetext{
* Corresponding author: author@e-mail.org
} 
strength of the legible characters of the Experimental Architecture design is the creativity in materials innovation and architectural technology. [4]

\section{Analysis and discussion}

\subsection{Problem identification}

Architecture is the Built Environment. The built environment is an environment characterized by the dominance of man-made structures. The built environment system depends on the existence of energy, resources, and human engineering to survive.

Architecture as a built environment in fact the focus of human fostering by enslaving the environment (nature). In its very nature it has outlined the natural resources created for the needs of architecture, but what architecture should understand is they are just borrowing instead of taking.

\subsubsection{The end of architecture}

The end of architecture in the world is quite threatening, but the development will continue to happen. Like an era, with the changing times will have a style or a mode that has a characteristic that makes it interesting and almost followed in its time.

Architecture will never die, it's just architects who have different roles. Principal architects will remain with their knowledge and will be outdone by technological advancements. But both can keep running, because without any thought created by humans, the system developed will not develop.

\subsubsection{Issues of deforestation}

Two architectural stages play a role in deforestation:

- The first stage, $25 \%$ of the world's forests are used for building construction material needs.

- The second stage, the buildings remove trees, with increasing percentage, city radius expanding and removing green areas [5].

In the global context deforestation has an impact:

- Over the last twenty years, 200 million hectares of forests have disappeared and about 15 million hectares have been destroyed each year.

- Temperature increased by $1.1{ }^{\circ} \mathrm{C}-6.4{ }^{\circ} \mathrm{C}$ between 1900-2000.

- Sea-level rise of $10-25 \mathrm{~cm}$ during the 20 th century.

- Water in the oceans is getting acidic because it absorbs a lot of carbon dioxide, destroying the food chain.

- Earth's temperature always increases $0.2{ }^{\circ} \mathrm{C}$ every year [6].

\subsection{Challenge analysis}

Architects who think always look at the problems that already exist, thinkers who think always look at the biggest problem. The problem of deforestation goes into the world's biggest architectural problem, and on the other hand the condition is always worsening, making the problem even more swelled leads the biggest row of trouble groups. The architect's challenge to deforestation is the survival of human life and nature. Man needs a house to live his life and so does the trees that need the land to live his life with humans.

Architecture greatly affects the destruction of nature. However, architects must have a way to create human sustainability without destroying nature. So that Man and Nature can live together, and nature still has its area to stand. To realize that side by side is to first understand what become unchangeable constants, forests or trees need the surface of the earth to live, while humans are more flexible to be able to live, humans only need "space". For that human being is accompanied by blessing thinking, this is where the right moment for us to succumb.

\subsection{Solution analysis}

Changing the human principle of "building displaces" to "neighbors", a way of realizing "neighborly building" rather than by building adjacent horizontally but vertically adjacent. Humans are given two choices, living above it or below it. In order to meet the realistic achievement of ideas in the next few years, it will be more appropriate to keep the dwelling below ground. Of course, the idea can be a rational doctrine to further develop like a developing architecture in this era and the family of previous generations.

\subsection{Design solutions}

Born from the problem of "unbalanced disputes for trees of human beings", Undersoil House is designed as an underground dwelling built with the aim of sharing space with plants, so that sustainable plants are on it.

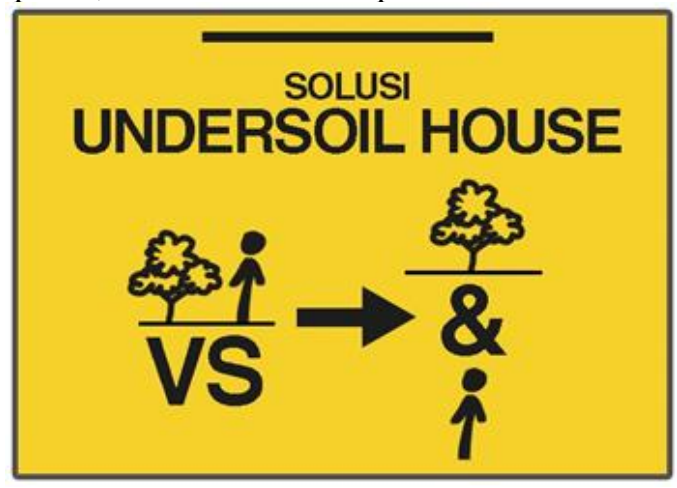

Fig. 1. Design solution: under soil house.

\subsubsection{The principle of solving deforestation solutions by undersoil house}

Man, certainly needs a house, and the house needs land, the concept of undersoil house is the land of the house on the surface not filled by the house but filled by the design of the plant. As for the house is positioned under the ground (undersoil house). Therefore, with the 
application of this undersoil house where there is a house (underground) there are trees (on the surface).

\subsubsection{From design to theory}

From the design of the undersoil house, will create several theories that will become a grip, in the era of architecture in the future:

a) Man Grows Plants.

b) Nature Man Powered, Human Nature Equals, Human Man Controlling, dan Nature Man Understood Nature.

c) The façade does not become important, replaced by the existence of plants, an era where humans lift prestige by raising plants, and lowering occupancy.

\subsubsection{Technology}

Here are some of the latest technologies applied to Undersoil house design:

\section{a) Thermofluid}

This type of pump is the most developed free energy pump technology developed by experts. They are researchers from Thermofluidic Ltd. which named this technology with the Non-Inertive-Feedback Thermofluidic Engine (NIFTE). This NIFTE technology does not use electrical energy at all, it just needs a source of heat like sun or geothermal to be able to pump water. [7] Non-inertive-Feedback Thermofluidic Engine (NIFTE), as a technology used to drive water waste upwards, with input energy from geothermal.

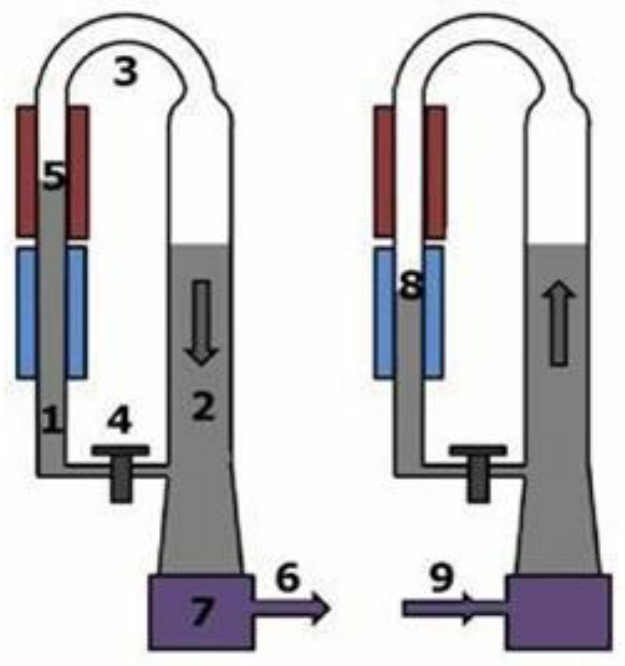

Fig. 2. Thermofluid technology.

The working principle of this pump is to use two cylinders $(1,2)$ containing interconnected water on the upper side (3) and bottom, at the bottom there is a throttle valve (4) or a kind of flow barrier. On the cylinder side (1) the heat source is illustrated with the red part, while the condenser or cooler is blue. When the water in cylinder 1 is heated by heat source 5 , there will be an expansion / evaporation so that the pressure inside the cylinder rises to reach the output pressure. This pressure will push the water in the cylinder 2 through the outlet side 7 and discharge check valve 6 . The water level on the cylinder 2 down causes the water in the cylinder (1) to move to the cylinder 2 due to the force of gravity. The water in the cylinder 1 reaches the condenser height (8) and undergoes a cooling process, causing the pressure inside the column (3) to drop and the water entering through the inlet tube 9 with a check valve. The water level inside the two cylinders is back up and the pump cycle keeps repeating from scratch again. [7]

\section{b) PLTMn (Pembangkit Listrik Tenaga Magnet) / Magnet Powerplant}

The fixed magnet generator, a newly developed technology, generates electricity without any source except the magnets inside, a small-sized magnet generator can produce up to $39 \mathrm{~kW}$, without any other energy input. Used as a dominant power plant in the house.

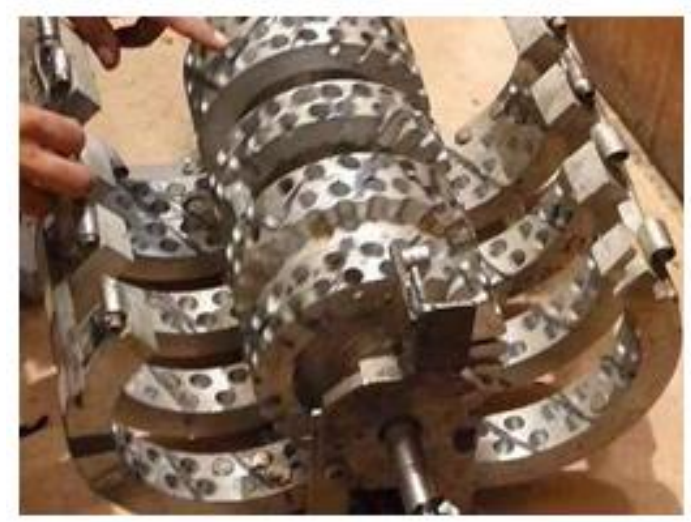

Fig. 3. PLTMn technology.

The advantages of PLTMn :

- Free and stable power source.

- Environmentally friendly, does not generate harmful gas and chemical emissions, and does not generate more heat.

- Can be operated under any weather conditions, very cold or very hot, both indoors and outdoors

- The shape can be small and cheap with materials that are easy to find where.

- Almost no care needed, if there are cheap maintenance costs. [8]

As an electric energy storage battery technology, delivered from the MHP generator, can accommodate up to $8 \mathrm{~kW}$ of electrical energy, prioritized in emergencies [8].

c) Sharp intelligent power conditioner

As an electric energy storage battery technology, delivered from the MHP generator, can accommodate up to $8 \mathrm{~kW}$ of electrical energy, prioritized in emergencies [8]. 


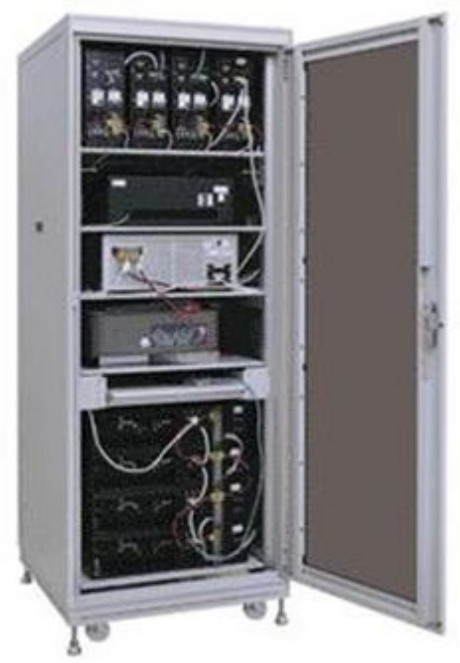

Fig. 4. Sharp intelligent power conditioner technology.

\section{Concept and design}

\subsection{Placement of residential design}

Under Soil House is one of the alternative design solutions for deforestation issues. Here's an explanation of the concept and design of an under-soil house. First about the placement of residential design. Residential Placement between the $\mathrm{C}$ and $\mathrm{Z}$ Horizon of the 5 horizons (Horizon O, A, B, E, C, Z). It is based on several considerations, such as:

- Has enough depth to give on plant root.

- Do not have organic elements of dwelling avoid the destruction of organisms that work in the ecosystem.

- Horizon C is composed of semi rock elements, Z strong enough parent rocks, can be utilized as a residential occupancy holder, so that occupancy remains in place and does not decrease.

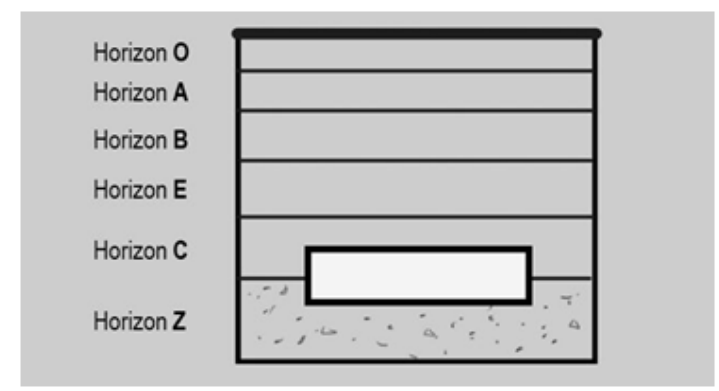

Fig. 5. Placement of residential design.

\subsection{Illustration of system and concept of urban soil house}

Urban Soil House concept is an underground residence, planning of design to respond to the survival of human life and nature. Humans no longer eliminate green areas but can live side by side with trees. Here's an Illustration of System and Concept Urban Soil House. The position of the house is in the ground, whereas the above is placed trees.

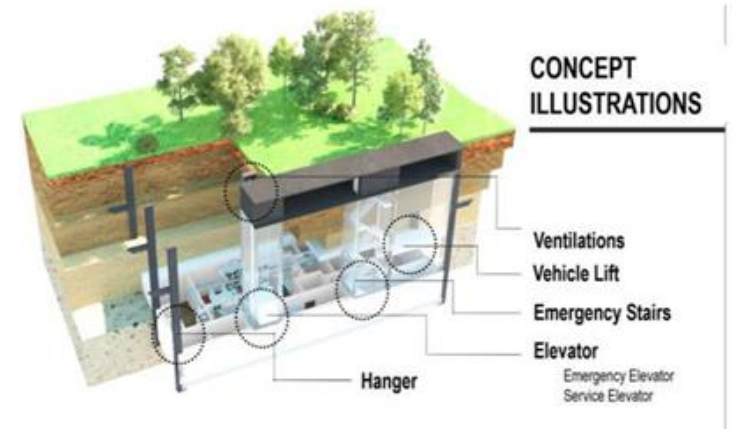

Fig. 6. Concept illustrations.

The important part of Under Soil house is Hanger, Ventilation, Elevator (Emergency Elevator and Service Elevator), Emergency Stairs, and Vehicle Lift. Under Soil House is designed with strong structures and building construction using retaining walls.

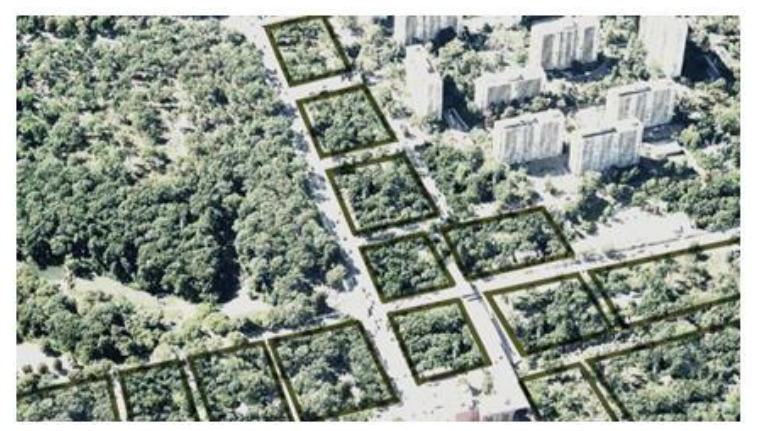

Fig. 7. Illustrations of residential groups.

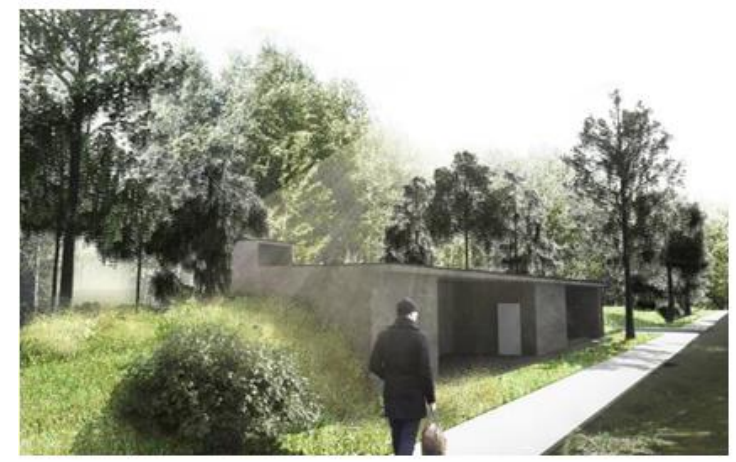

Fig. 8. Illustrations of fasade under soil house.

\section{Conclusions}

Architecture will never die, because every age has its own style. It's just that architects will have different roles. They may become a principal architect, who can create an innovation that can be developed in a growing technology. Architecture does not stand alone. Architectural part of nature and human culture. In contrast, the architecture also needs to behave or respond according to natural conditions and what happens in the society's thinking. Architecture is not value-free, architectural form is the implementation of a series of attitudes, choices, responses to various problems or challenges faced both in the function of the building itself, as well as the involvement of all things in it, when 
architecture embodies the needs of all living elements, become the scientific field in the highest position. Under Soil House is one of the alternative design solutions for deforestation issues. Urban Soil House concept is an underground residence, planning of design to respond the survival of human life and nature. Humans no longer eliminate green areas but can live side by side with trees.

\section{Acknowledgment}

First of all, on this occasion, I would like to thanks to the preceptor who have provided guidance for preparing the paper substance Prof. DR. MS. Barliana and Indah Susanti.

\section{References}

1. A. Bukhori M, Pembangunan Hutan Pasca Reformasi (2014)

2. S. Sathista, Defortasi Penggundulan Hutan (2015)

3. P. Cook, Experimental Architecture (1970)

4. A. Betsky, The Pedagogy of Experimental Architecture (1994)

5. R. Carter, Desforestation \& Architecture (2007)

6. Y. Sing, Interdependensi Alam-Budaya-Arsitektur (2013)

7. O. Onny, Pompa Bebas Energi (2018)

8. F. Fagi, Magnet Tetap sebagai Sumber Energi Terbarukan (2018) 